\title{
Low pretreatment PNI correlates with worse survival in patients with stage III/ IV NSCLC who received chemotherapy
}

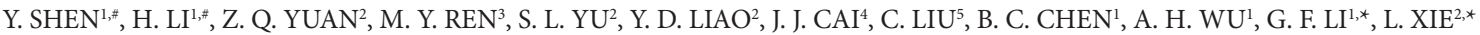 \\ ${ }^{1}$ Department of 1Thoracic Surgery, ${ }^{2}$ Internal Medicine, ${ }^{3}$ Radiology, ${ }^{4}$ Key Laboratory of Lung Cancer Research of Yunnan Province, ${ }^{5}$ Nuclear \\ Medicine, The Third Affiliated Hospital of Kunming Medical University (Yunnan Cancer Hospital, Yunnan Cancer Center), Kunming Medical \\ University, Kunming, 650118, China
}

*Correspondence: ligaofeng698@163.com; xielinyanghan@163.com

${ }^{*}$ Contributed equally to this work.

Received April 1, 2019 / Accepted July 16, 2019

\begin{abstract}
The aim of this study was to investigate the prognostic value of the prognostic nutritional index (PNI) on the long-term survival of non-small cell lung cancer (NSCLC) patients who received platinum-based chemotherapy. Data on nutritional parameters and clinicopathological characteristics [e.g., albumin, total protein, body mass index (BMI), eastern cooperative oncology group (ECOG) performance status, stage, pathology, treatment strategy] were analyzed and retrospectively correlated with overall survival (OS). The PNI was calculated based on the concentration of albumin and lymphocyte count $\left[10 \times\right.$ albumin, $(\mathrm{g} / \mathrm{dl})+0.005 \times$ lymphocyte $\left(\right.$ count $\left.\left./ \mathrm{mm}^{3}\right)\right]$. A receiver operating characteristic curve (ROC) analysis was used to find the optimal cut-off value of PNI. Univariate and multivariate analyses were used to evaluate the prognostic value of PNI. A total of 186 patients met the inclusion criteria. The optimal cut-off value for PNI was 50.45. Compared with the parameters of the low PNI group $(n=76)$, high PNI was significantly associated with adenocarcinoma type, stage III, better ECOG and comprehensive treatment modality. The univariate analysis demonstrated that OS was superior when PNI $\geq 50.45$, albumin $\geq 35 \mathrm{~g} / \mathrm{l}$, platelet-lymphocyte ratio (PLR) $\geq 163$ and ECOG $<2$, and when the patient received a comprehensive treatment modality. In the multivariate analysis, PNI, TNM stage and treatment strategy were identified as independent predictors of survival in this study. This retrospective study demonstrated that a low PNI was related to worse overall survival in patients with stage III/IV NSCLC who received platinum-based chemotherapy. These data provided a conceptual basis for further research on the clinical application of the PNI index for patients receiving chemotherapy for intermediateand advanced-stage NSCLC.
\end{abstract}

Key words: prognostic nutrition index, survival, non-small cell lung cancer, platinum-based chemotherapy

Lung cancer continues to be the leading cause of cancerrelated mortality around the world, according to the data from 2018 [1]. Non-small cell lung cancer (NSCLC) accounts for $85-90 \%$ of newly diagnosed lung cancer, of which $66 \%$ were at middle or late stages [2], and the prognosis of patients with NSCLC remains disappointing.

Chemotherapy plays an important role in the NSCLC multidisciplinary treatment modalities when combined with surgery, radiotherapy, target therapy and immunotherapy. However, platinum drug-related symptoms such as anorexia, nausea, vomiting and constipation usually induce the deterioration of nutritional status $[3,4]$. On the other hand, baseline nutritional deficiencies are prevalent in cancer and have been revealed to be related to decreased tolerance of chemotherapy [5], poor life quality and inferior clinical outcomes [6]. Furthermore, nutrition support therapy was reported to be helpful in maintaining patients' weight level [7], decreasing therapy breaks for toxicity [8] and obtaining survival benefits [9-11]. Notably, identifying the nutrition risks before treatment initiation through convenient and cost-effective methods is of great value.

Prognostic nutritional index (PNI) is an index that comprehensively reflects the nutritional and immunological status of patients. PNI was calculated based on the concentration of albumin and lymphocyte count $[10 \times$ albumin, $(\mathrm{g} / \mathrm{dl})$ $+0.005 \times$ lymphocyte $\left(\right.$ count $\left.\left./ \mathrm{mm}^{3}\right)\right]$. PNI was originally presented by Onodera et al. in 1984, and was applied to relate the risk of postoperative complications to baseline nutrition status in gastric cancer [12]. To date, PNI has been discovered to be a predictor of survival in a variety of malignancies 
[13-15]. However, little is known about the prognostic value of PNI in patients with stage III/IV NSCLC who received chemotherapy. In this study, we observed the relationship between nutrition status and clinicopathological characteristics, and evaluated the prognostic value of PNI for survival through univariate and multivariate analyses in treatmentnaive NSCLC patients.

\section{Patients and methods}

Patient selection. Medical records of 186 patients who were first diagnosed with stage III/IV NSCLC from June 2014 to December 2014 were retrieved and retrospectively analyzed. All patients received first-line platinum-based chemotherapy with or without other treatment methods. Patients were excluded based on the following criteria: 1) diagnosed of other primary cancer(s); 2) received anticancer treatment before being admitted to our hospital; and 3) did not have complete clinical information. Staging was performed according to the 2002 Union for International Cancer Control (UICC) TNM classification. This retrospective study was approved by the Medical Ethics Committee of our hospital.

Data collection. The main purpose of this study was to investigate the prognostic value of pretreatment nutrition parameters, including the PNI index, in stage III/IV NSCLC patients who received first-line chemotherapy. The main treatment methods applied from the day of diagnosis to the study endpoint were recorded. Data collected included patient demographics (age and gender), medical history (pathological pattern, TNM stage, smoking history, ECOG score, BMI), laboratory parameters (albumin, lymphocyte cell count, neutrophil granulocyte count, platelet count), and the date from diagnosis until death (overall survival).

Follow-up and statistical analysis. Overall survival (OS) was calculated from the day of the pathological diagnosis of NSCLC until death. The endpoint of this study was June 31, 2016. Patients lost to follow-up were censored at the time of the last visit or observation. Continuous variables are shown as the means and standard deviations (SDs). Percentages are provided for categorical variables. Student's t-test and analysis of variance (ANOVA) were used for comparing continuous variables from two or more independent samples. The chi-square test was used for comparing categorical variables. Receiver operating characteristic curve (ROC) analysis was used to find the optimal cut-off value of the PNI index for predicting OS. For survival analysis, the Kaplan-Meier method was used to estimate the probability of OS. Survival curves between groups were compared by the log-rank test. Significant factors identified from the univariate analysis and clinical factors that may be related to survival were entered into the multivariate Cox regression model to test for independent prognostic factors. P-values less than $5 \%$ were considered statistically significant.

SPSS software (IBM SPSS Statistics for Windows, Version 20.0) was used to perform the statistical analysis.

\section{Results}

Patient characteristics. The clinical characteristics of 186 stage III/IV NSCLC patients are shown in Table 1. A total of 138 male patients (74.2\%) and 48 female patients (25.8\%) were included in this study. The age of patients at diagnosis ranged from 31 to 80 years, and the median was 56 years. Adenocarcinoma (56.7\%) and squamous carcinoma (38.5\%) constituted the main pathological types, and other types (4.8\%) included adeno-squamous carcinoma, neuroendocrine carcinoma, large cell carcinoma, alveolar carcinoma, poorly differentiated carcinoma and lymphoepithelial carcinoma. Of the included patients, 78 patients $(41.9 \%)$ received platinum-based chemotherapy only, while 39 patients $(21.0 \%)$ received combined surgery, 31 patients (16.7\%)

Table 1. Clinical characteristics of the included patients.

\begin{tabular}{|c|c|c|}
\hline Characteristic & Variable & Patients, n (\%) \\
\hline \multirow[t]{2}{*}{ Gender } & Male & $138(74.2)$ \\
\hline & Female & $48(25.8)$ \\
\hline \multirow[t]{2}{*}{ Age } & Mean \pm SD & $56.12 \pm 9.91$ \\
\hline & Median (range) & $56(31-80)$ \\
\hline \multirow[t]{2}{*}{ Smoking } & Yes & $93(50.0)$ \\
\hline & No & $93(50.0)$ \\
\hline \multirow[t]{3}{*}{ Pathological Pattern } & $\mathrm{ADC}$ & $105(56.5)$ \\
\hline & SCC & $72(38.7)$ \\
\hline & other types & $9(4.8)$ \\
\hline \multirow[t]{2}{*}{ TNM Stage } & III & $97(52.2)$ \\
\hline & IV & $89(47.8)$ \\
\hline \multirow[t]{2}{*}{ BMI } & Mean \pm SD & $22.33 \pm 2.77$ \\
\hline & Median (range) & $21.97(16.00-29.07)$ \\
\hline \multirow[t]{3}{*}{ ECOG } & 0 & $14(7.5)$ \\
\hline & 1 & $159(85.5)$ \\
\hline & $\geq 2$ & $13(7.0)$ \\
\hline \multirow[t]{2}{*}{ NRS score } & NRS $\geq 3$ & $59(31.7)$ \\
\hline & NRS $<3$ & $127(68.3)$ \\
\hline \multirow[t]{2}{*}{$\operatorname{Albumin}(\mathrm{g} / \mathrm{L})$} & Mean \pm SD & $41.76 \pm 5.13$ \\
\hline & Median (range) & $42.00(25.00-53.00)$ \\
\hline \multirow[t]{2}{*}{ PNI } & Mean \pm SD & $51.26 \pm 6.57$ \\
\hline & Median (range) & $52.50(31.25-66.50)$ \\
\hline \multirow[t]{2}{*}{ PLR } & Mean \pm SD & $164.64 \pm 86.97$ \\
\hline & Median (range) & $144.00(41.85-651.79)$ \\
\hline \multirow[t]{2}{*}{ NLR } & Mean \pm SD & $4.09 \pm 13.09$ \\
\hline & Median(range) & $2.52(0.02-179.08)$ \\
\hline \multirow{2}{*}{ Treatment strategy } & Comprehensive modality & $108(58.1)$ \\
\hline & Chemo-only & $78(41.9)$ \\
\hline
\end{tabular}

Abbreviation: ADC, adenocarcinoma;; Non-ADC: Non-adenocarcinoma; SCC, squamous carcinoma; BMI, body mass index; ECOG, Eastern Cooperative Oncology Group performance status; NRS, nutrition risk screening 2002; PNI, prognostic nutritional index; PLR, platelet-lymphocyte ratio; NLR, neutrophil-lymphocyte ratio; Comprehensive modality: Chemotherapy combined with at least one other treatment method: surgery, radiotherapy, target therapy, immunotherapy, antiangiogenic therapy, interventional treatment and gamma knife radiosurgery et al.; Chemo-only: platinumbased chemotherapy only during the treatment courses. 
received radiotherapy, 23 patients $(12.4 \%)$ received more than two treatment methods in addition to chemotherapy, 13 patients $(7.0 \%)$ received combined target therapy according to the results of the EGFR/ALK mutation test, and 2 patients (1.1\%) received combined immunotherapy/antiangiogenic therapy. Fifty-nine patients (31.7\%) fell into the category of nutritional risk (nutritional risk screen-NRS $\geq 3$ ).

The relationship between clinicopathological characteristics and nutrition parameters. As shown in Table 2, some frequently used nutritional parameters tended to be different among patients grouped by clinical characteristics. The mean values of albumin and total protein (TP) were significantly higher in patients with better $($ ECOG $<2)$ performance status (albumin: $42.08 \pm 5.03 \mathrm{~g} / \mathrm{l}$ vs $37.54 \pm 4.72, \mathrm{p}=0.002$; TP: $71.21 \pm 6.68$ vs $66.69 \pm 8.73, \mathrm{p}=0.023$ ), while the platelet count level was higher in patients with worse $(E C O G \geq 2)$ performance status (platelet: $271.73 \pm 84.78$ vs $323.15 \pm 111.81$, $\mathrm{p}=0.041$ ). In patients who received comprehensive treatment modalities, the levels of albumin and TP were higher than in those who received chemotherapy only (albumin: $42.67 \pm 4.42$ vs $40.47 \pm 5.79, \mathrm{p}=0.004$; TP: $72.22 \pm 6.07$ vs $69.01 \pm 7.60$, $\mathrm{p}=0.002$ ). In addition, the total protein level was higher in stage III patients (III vs IV: $72.43 \pm 6.16$ vs $69.21 \pm 7.32$, $\mathrm{p}=0.001$ ), and the albumin level was higher in patients with adenocarcinoma (ADC vs Non-ADC: $42.70 \pm 5.19$ vs $40.54 \pm 4.82, \mathrm{p}=0.004)$. No direct correlation between lymphocyte count and these characteristics was found.

The correlation of the PNI index and albumin with clinicopathological characteristics is shown in Table 3. High
PNI (PNI $\geq 50.45$ ) was significantly related to earlier stage $(p=0.016)$, comprehensive treatment modalities $(p=0.017)$, better ECOG performance status $(\mathrm{p}=0.032)$ and adenocarcinoma ( $\mathrm{p}=0.013)$. High albumin was only significantly related to gender and treatment strategy.

Univariate and multivariate analyses of overall survival of 183 patients. At the time of analysis, 80 (43.7\%) patients had died. Three patients were lost to follow-up. The mean value of OS was $15.49 \pm 0.71$ months for all patients. The ROC analysis showed that the optimal PNI cut-off was 50.45 ( $\mathrm{p}=0.008$, AUC, $0.615 ; 95 \%$ CI, 0.532-0.699) for overall survival. The patients were then divided into high PNI $(\geq 50.45)$ and low PNI $(<50.45)$ groups. There were 110 patients in the high PNI group and 76 patients in the low PNI group.

Univariate analysis (Table 4) of predictive factors of OS showed that nutritional parameters, namely, PNI $\geq 50.45$, serum albumin $\geq 35 \mathrm{~g} / \mathrm{L}$, and PLR $\geq 163$, were strongly correlated with a longer OS. Comprehensive treatment modalities, stage III and ECOG $<2$ were the clinicopathological factors that predicted a better OS.

In the multivariate analysis (Table 5), PNI [HR 0.457 (0.291-0.717)], TNM stage [HR 2.423 (1.497-3.921)] and treatment strategy [HR $0.359(0.225-0.573)$ ] were identified as independent predictors of OS in NSCLC patients. The median $(95 \%$ CI) OS in patients in the high PNI group was longer than that in the patients in the low PNI group [17.90 (16.26-19.53) months versus 11.86 (9.65-14.07) months, respectively (HR 0.466, 95\% CI 0.298-0.729; p $<0.001$;

Table 2. Correlation of nutritional laboratory parameters with clinicopathological characteristics.

\begin{tabular}{|c|c|c|c|c|c|c|c|c|}
\hline \multirow[t]{2}{*}{ Characteristics } & \multicolumn{2}{|c|}{$\begin{array}{c}\text { Albumin } \\
(\mathrm{g} / \mathrm{l})\end{array}$} & \multicolumn{2}{|c|}{$\begin{array}{l}\text { Total Protein } \\
(\mathrm{g} / \mathrm{l})\end{array}$} & \multicolumn{2}{|c|}{$\begin{array}{l}\text { Platelet count } \\
\qquad\left(\times 10^{9} / 1\right)\end{array}$} & \multicolumn{2}{|c|}{$\begin{array}{c}\text { Lymphocyte count } \\
\left(\times 10^{9} / 1\right)\end{array}$} \\
\hline & Mean & SD & Mean & SD & Mean & SD & Mean & SD \\
\hline \multicolumn{9}{|l|}{ Pathological type } \\
\hline Non-ADC & 40.54 & 4.82 & 70.90 & 6.80 & 278.59 & 94.41 & 1.92 & 0.68 \\
\hline $\mathrm{ADC}$ & 42.70 & 5.19 & 70.89 & 7.03 & 272.81 & 82.26 & 1.88 & 0.63 \\
\hline $\mathrm{p}$-value & & $0.004^{\star}$ & & 0.988 & & 0.656 & & 0.682 \\
\hline \multicolumn{9}{|l|}{ TNM Stage } \\
\hline III & 42.34 & 4.55 & 72.43 & 6.16 & 268.36 & 86.98 & 1.95 & 0.64 \\
\hline IV & 41.13 & 5.66 & 69.21 & 7.32 & 282.92 & 88.04 & 1.84 & 0.65 \\
\hline $\mathrm{p}$-value & & 0.11 & & $0.001^{*}$ & & 0.26 & & 0.23 \\
\hline \multicolumn{9}{|l|}{ NRS score } \\
\hline NRS $<3$ & 42.17 & 4.93 & 71.45 & 6.50 & 268.80 & 85.43 & 1.91 & 0.65 \\
\hline $\mathrm{NRS} \geq 3$ & 40.88 & 5.48 & 69.69 & 7.63 & 289.37 & 91.14 & 1.88 & 0.65 \\
\hline v-value & & 0.11 & & 0.11 & & 0.14 & & 0.84 \\
\hline \multicolumn{9}{|l|}{ ECOG } \\
\hline$<2$ & 42.08 & 5.03 & 71.21 & 6.68 & 271.73 & 84.78 & 1.87 & 0.62 \\
\hline$\geq 2$ & 37.54 & 4.72 & 66.69 & 8.73 & 323.15 & 111.81 & 2.22 & 0.85 \\
\hline $\mathrm{p}$-value & & $0.002^{*}$ & & $0.023^{\star}$ & & $0.041^{\star}$ & & 0.064 \\
\hline \multicolumn{9}{|l|}{ Treatment strategy } \\
\hline Comprehensive modality & 42.67 & 4.42 & 72.22 & 6.07 & 270.91 & 85.34 & 1.94 & 0.66 \\
\hline Chemo-only & 40.47 & 5.79 & 69.01 & 7.60 & 281.58 & 90.79 & 1.84 & 0.63 \\
\hline $\mathrm{p}$-value & & $0.004^{*}$ & & $0.002^{*}$ & & 0.414 & & 0.296 \\
\hline
\end{tabular}


Table 3. Characteristics of 186 stage III/IV NSCLC patients grouped by albumin and PNI index.

\begin{tabular}{|c|c|c|c|c|c|c|}
\hline \multirow[b]{2}{*}{ Characteristics } & \multicolumn{2}{|c|}{ PNI } & \multirow[b]{2}{*}{ p-value } & \multicolumn{2}{|c|}{ Albumin } & \multirow[b]{2}{*}{ p-value } \\
\hline & $\begin{array}{l}\geq 50.45 \\
(n=110)\end{array}$ & $\begin{array}{l}<50.45 \\
(\mathrm{n}=76)\end{array}$ & & $\geq 35 \mathrm{~g} / \mathrm{L}$ & $<35 \mathrm{~g} / \mathrm{L}$ & \\
\hline \multicolumn{7}{|l|}{ Age } \\
\hline$<60$ & 72 & 43 & 0.142 & 105 & 10 & 0.369 \\
\hline$\geq 60$ & 38 & 33 & & 63 & 8 & \\
\hline \multicolumn{7}{|l|}{ Gender } \\
\hline Male & 85 & 53 & 0.162 & 121 & 17 & $0.028^{*}$ \\
\hline Female & 25 & 23 & & 47 & 1 & \\
\hline \multicolumn{7}{|l|}{ Smoking history } \\
\hline No & 53 & 40 & 0.327 & 85 & 8 & 0.402 \\
\hline Yes & 57 & 36 & & 83 & 10 & \\
\hline \multicolumn{7}{|l|}{ Pathological type } \\
\hline Non-ADC & 40 & 41 & $0.013^{\star}$ & 70 & 11 & 0.092 \\
\hline $\mathrm{ADC}$ & 70 & 35 & & 98 & 7 & \\
\hline \multicolumn{7}{|l|}{ TNM Stage } \\
\hline III & 65 & 32 & $0.016^{*}$ & 89 & 8 & 0.329 \\
\hline IV & 45 & 44 & & 79 & 10 & \\
\hline \multicolumn{7}{|l|}{ Strategy } \\
\hline $\begin{array}{l}\text { Comprehensive } \\
\text { modality }\end{array}$ & 72 & 37 & $0.017^{*}$ & 104 & 5 & $0.006^{*}$ \\
\hline Chemo-only & 38 & 39 & & 64 & 13 & \\
\hline \multicolumn{7}{|l|}{ NRS score } \\
\hline NRS $<3$ & 78 & 49 & 0.221 & 118 & 9 & 0.071 \\
\hline $\mathrm{NRS} \geq 3$ & 32 & 27 & & 50 & 9 & \\
\hline \multicolumn{7}{|l|}{ ECOG } \\
\hline$<2$ & 106 & 67 & $0.032^{\star}$ & 158 & 15 & 0.117 \\
\hline$\geq 2$ & 4 & 9 & & 10 & 3 & \\
\hline
\end{tabular}

Figure 1A)]; patients with stage IV NSCLC lived for a shorter time than those with stage III [12.07 (9.99-14.15) months versus 18.64 (17.02-20.26) months, respectively (HR 2.137, 95\% CI 1.339-3.412; p<0.001; Figure 1B)]. Patients who received a comprehensive treatment modality had better survival than those who received chemotherapy only [18.45 (16.93-19.96) months versus 10.53 (8.28-12.78) months, respectively (HR $0.379,95 \%$ CI $0.239-0.603 ; \mathrm{p}<0.001$; Table 5, Figure 1C)].

\section{Discussion}

Our study demonstrated that PNI, TNM stage and treatment strategy are independent predictors of survival in stage III/IV NSCLC patients who received platinum-based chemotherapy.

Cancer patients are usually at a high risk of malnutrition prior to any treatment $[16,17]$ because of the tumor itself. The possible mechanisms include cancer-related symptoms (fatigue, pain, coughing and loss of appetite), abnormal energy and protein metabolism of cancer cells and aberrant systemic inflammatory reactions. Baseline nutrition problems have been demonstrated to be prevalent
Table 4. Univariate analysis of overall survival in stage III/IV NSCLC patients.

\begin{tabular}{|c|c|c|c|}
\hline Characteristics & $\begin{array}{c}\text { Patients, } \\
\text { n (\%) }\end{array}$ & Months (95\% CI) & p-value \\
\hline \multicolumn{4}{|l|}{ Gender } \\
\hline Male & $136(74.2)$ & $15.62(14.01-17.30)$ & \multirow{2}{*}{0.653} \\
\hline Female & $47(25.8)$ & $15.07(12.43-17.71)$ & \\
\hline \multicolumn{4}{|l|}{ Age } \\
\hline$<60$ & $113(61.7)$ & $15.92(14.14-17.70)$ & \multirow{2}{*}{0.698} \\
\hline$\geq 60$ & $70(38.3)$ & $14.91(12.69-7.13)$ & \\
\hline \multicolumn{4}{|l|}{ Smoking } \\
\hline Yes & $92(50.3)$ & $15.15(13.225-17.07)$ & \multirow{2}{*}{0.482} \\
\hline No & $91(49.7)$ & $15.89(13.86-17.91)$ & \\
\hline \multicolumn{4}{|l|}{ Pathological Pattern } \\
\hline $\mathrm{ADC}$ & $102(55.7)$ & $15.01(13.13-16.90)$ & \multirow{2}{*}{0.461} \\
\hline Non-ADC & $81(44.3)$ & $16.09(14.02-18.15)$ & \\
\hline \multicolumn{4}{|l|}{ TNM Stage } \\
\hline III & $96(52.5)$ & $18.64(17.02-20.26)$ & \multirow{2}{*}{$<0.001^{\star}$} \\
\hline IV & $87(47.5)$ & $12.07(9.99-14.15)$ & \\
\hline \multicolumn{4}{|l|}{ Albumin } \\
\hline$\geq 35 \mathrm{~g} / \mathrm{L}$ & $165(90.2)$ & $16.04(14.61-17.47)$ & \multirow{2}{*}{$0.016^{*}$} \\
\hline$<35 \mathrm{~g} / \mathrm{L}$ & $18(9.8)$ & $10.68(5.86-15.50)$ & \\
\hline \multicolumn{4}{|l|}{ NRS score } \\
\hline NRS $<3$ & $125(68.3)$ & $16.25(14.58-17.92)$ & \multirow{2}{*}{0.067} \\
\hline $\mathrm{NRS} \geq 3$ & $58(31.7)$ & $13.76(11.29-16.24)$ & \\
\hline \multicolumn{4}{|l|}{ ECOG } \\
\hline$<2$ & $170(92.9)$ & $16.02(14.57-17.46)$ & \multirow{2}{*}{$0.003^{*}$} \\
\hline$\geq 2$ & $13(7.1)$ & $8.97(5.19-12.74)$ & \\
\hline \multicolumn{4}{|l|}{ PLR } \\
\hline$\geq 163$ & $111(60.7)$ & $16.82(15.08-18.56)$ & \multirow{2}{*}{$0.011^{*}$} \\
\hline$<163$ & $72(39.3)$ & $13.28(11.06-15.51)$ & \\
\hline \multicolumn{4}{|l|}{ NLR } \\
\hline$\geq 5$ & $23(12.57)$ & $12.40(8.46-16.34)$ & \multirow{2}{*}{0.094} \\
\hline$<5$ & $160(87.43)$ & $15.87(14.39-17.35)$ & \\
\hline \multicolumn{4}{|l|}{ PNI } \\
\hline$\geq 50.45$ & $109(59.56)$ & $17.90(16.26-19.53)$ & \multirow{2}{*}{$<0.001^{*}$} \\
\hline$<50.45$ & $74(40.44)$ & $11.86(9.65-14.07)$ & \\
\hline \multicolumn{4}{|l|}{ Treatment strategy } \\
\hline Comprehensive modality & $107(58.47)$ & $18.45(16.93-19.96)$ & \multirow{2}{*}{$<0.001^{\star}$} \\
\hline Chemo-only & $76(41.53)$ & $10.53(8.28-12.78)$ & \\
\hline
\end{tabular}

Table 5. Multivariate analysis of overall survival in stage III/IV NSCLC patients.

\begin{tabular}{lll}
\hline Variables & $\begin{array}{l}\text { Hazard Ratio } \\
\mathbf{( 9 5 \% ~ C I )}\end{array}$ & p-value \\
\hline PNI $(\geq 50.45 /<50.45)$ & $0.466(0.298-0.729)$ & 0.001 \\
TNM stage (IV/III) & $2.137(1.339-3.412)$ & 0.001 \\
$\begin{array}{l}\text { Treatment strategy } \\
\text { (Comprehensive modality/Chemo-only) }\end{array}$ & $0.379(0.239-0.603)$ & $<0.001$ \\
\hline
\end{tabular}

among lung cancer patients, of whom approximately $34-69 \%$ experienced malnutrition $[18,19]$, while the percentage of patients with nutrition risk might be higher. Our study found that $40.9 \%$ of patients had a PNI $<50.45$ (related to worse survival), $31.4 \%$ had an NRS $\geq 3$ (regarded as nutritional 
A

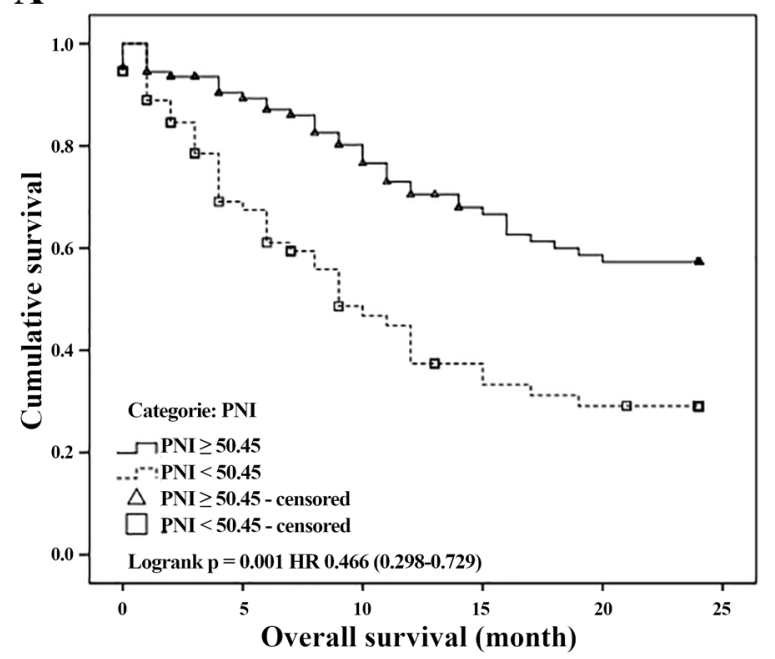

C

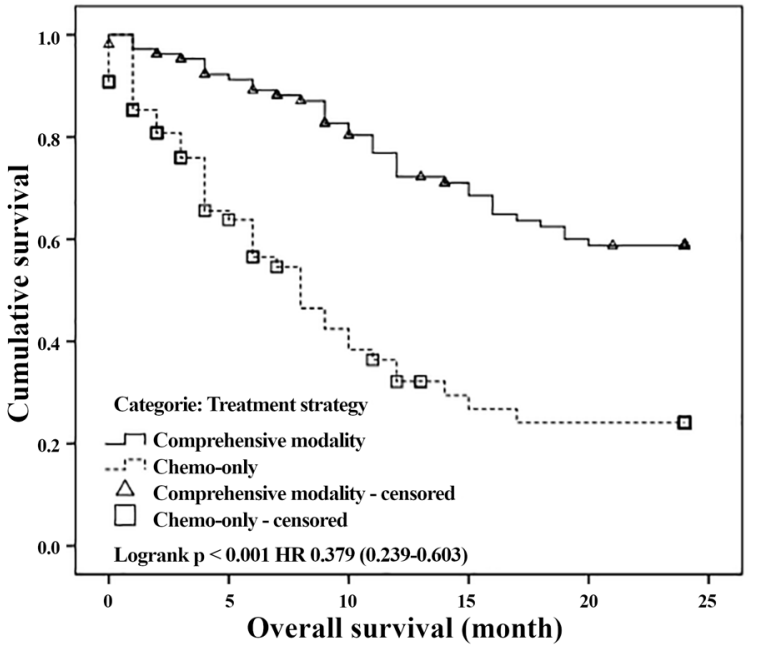

risk) and only $7.5 \%$ had BMI $<18.5$ (regarded as malnutrition). This finding reminds us that PNI may be more sensitive when used for identifying potential nutritional problems in NSCLC patients.

Baseline nutrition status was traditionally evaluated with parameters and systemic inflammatory reaction biomarkers. Studies have shown that serum albumin [20], body mass index (BMI) [21], physical performance [22, 23], and quality of life [24] are related to the prognosis of cancer patients. Our results suggested that higher albumin or total protein (TP) was correlated with ECOG $<2$ and comprehensive treatment modality. Albumin was a predictor of OS in the univariate analysis that was performed in this study. It could be inferred that albumin and total protein may be valuable in reflecting patients' physical performance status, which was possibly a key premise of optimal treatment and better survival outcomes.

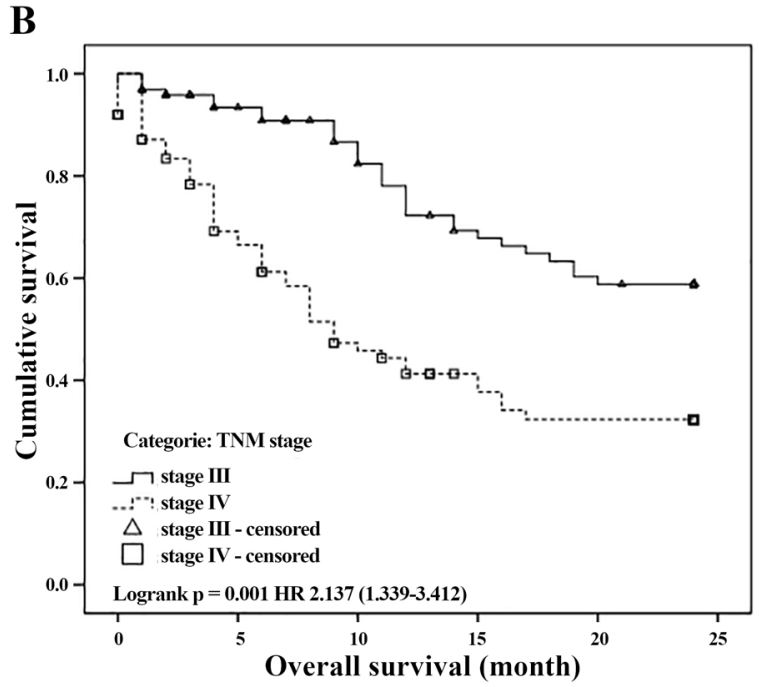

Figure 1. The median OS in patients in the high PNI group (A) was longer than those in the low PNI group [17.90 (16.26-19.53) months versus 11.86 (9.65-14.07) months, respectively]; in patients with stage IV NSCLC (B) was worse than those with stage III disease [12.07 (9.9914.15) months versus $18.64(17.02-20.26)$ months, respectively]; in patients who received a comprehensive treatment modality $(C)$ was better than those who received chemotherapy only $[18.45(16.93-19.96)$ months versus $10.53(8.28-12.78)$ months, respectively].

However, it is not sufficient for oncologists to reach a clinical determination based on albumin and TP only. Comprehensive indexes with more information are needed. In previous studies, systemic inflammatory biomarkers and indexes such as PNI, neutrophil-lymphocyte ratio (NLR), and platelet-lymphocyte ratio (PLR) have been demonstrated to be important prognostic factors, independent of primary tumor site $[25,26]$. In this study, however, NLR and PLR showed no significance in the multivariate analysis. PLR was found to be related to survival in the univariate analysis. PNI was positively correlated with OS both in the univariate analysis and the multivariate analysis.

PNI is an index reflecting systemic immunonutritional status of patients. Large amounts of evidence indicate that higher PNI values are independently associated with better survival in malignancies, including gastric cancer [27], colorectal cancer $[28,29]$, lung cancer $[30,31]$, head and 
neck cancer [32] and renal cell cancer [33]. A similar study conducted by Hong et al. [14] found that PNI $\geq 52.48$ was an independent predictor of longer OS compared with low PNI group in patients with small cell lung cancer (SCLC), yielding a significant reduction in mortality risk of $38 \%$. The research discovered that, besides PNI, other factors including ECOG $<2$, normal LDH (lactate dehydrogenase) and limited disease were also independent predictors of OS in SCLC patients. What was different in our study is that pathology type and general treatment strategy were put into survival analysis considering the heterogeneity of subtypes of NSCLC. Furthermore, other nutritional and inflammatory indexes including NRS, NLR, PLR were calculated and compared with PNI, which was not done in the study mentioned above. The results of our study showed that PNI, together with TNM stage and treatment modality, were independent prognostic factors for OS in NSCLC patients whose treatment modalities included platinum-based chemotherapy. In the multivariate analysis, we observed a $54.3 \%$ reduction in the mortality risk in the high PNI group $(\geq 50.45)$ when compared to the mortality risk of the low group (Table 4 ).

In patients stratified by the PNI index, variables including age, gender, smoking history and NRS were similar between the two groups. Higher PNI was significantly related to adenocarcinoma type, a stage classification of III, ECOG $<2$ and comprehensive treatment modality (Table 3 ). When compared to albumin, which was only associated with gender and treatment strategy, PNI was able to distinguish patients with potential nutritional deficiencies from the others.

Treatment strategy was stratified into two groups in our study: 1) chemotherapy only; and 2) chemotherapy combined with at least one other anti-cancer treatment method. The comprehensive modality group was positively correlated with higher concentrations of albumin $(\mathrm{p}=0.004)$ and TP $(\mathrm{p}=0.002)$. When stratified by PNI and albumin, we observed that the comprehensive treatment strategy group was significantly correlated with PNI $\geq 50.45$ or albumin $\geq 35 \mathrm{~g} / \mathrm{l}$. It could be inferred that whether a more comprehensive treatment strategy was acceptable to patients may be affected by baseline nutrition status and immunological conditions.

Considering the fact that PNI has been reported to be related to the compliance of chemotherapy [34], this would serve as an explanation why higher PNI levels correlate with better OS in NSCLC patients since the possibility of receiving optimal treatment would be higher in those with a PNI $\geq 50.45$.

As a result, our study verified the prognostic value of PNI as an independent predictor of overall survival in stage III/ IV NSCLC patients who received platinum-based chemotherapy. In addition, TNM stage and treatment modality were also identified as independent predictors of OS in this study. In conclusion, PNI may be useful for identifying potential nutritional problems and guiding oncologists to provide appropriate interventions before treatment initiation.

This study provided a conceptual basis for a prospective study exploring the correlation of baseline nutritional status with the clinical outcomes in NSCLC patients who had an acceptable condition to initiate anti-cancer treatment. There are limitations of our study related to not including a larger number of patients, who received chemotherapy combined with target therapy or immunotherapy as these treatments have become increasingly important in first-line anticancer treatment. However, the results of our study still presented the potential of PNI for predicting patient survival independent of other features, including treatment strategy and stage. Nevertheless, further investigations and prospective clinical trials are needed to confirm the significance of the PNI nutritional index in predicting clinical outcomes.

Acknowledgments: This research was supported in part by a grant (No.2018D012) from the PHD Innovation Fund of Kunming Medical University, a grant (No. 2018NS0072) from the Internal Institution Project of Ministry of Health of Yunnan Province, grants (No.81760554, No.81460356, No.81560471 and No.81760520) from the National Natural Science Foundation of China, a grant (2017FE467(-083)) from the Joint Funds for the Department of Science and Technology of Yunnan Province-Kunming Medical University, and a grant (No.2017YFC1308704) from the National Key Research and Development Project for the Ministry of Science and Technology of China.

\section{References}

[1] BRAY F, FERLAY J, SOERJOMATARAM I, SIEGEL RL, TORRE LA et al. Global cancer statistics 2018: GLOBOCAN estimates of incidence and mortality worldwide for 36 cancers in 185 countries. CA Cancer J Clin 2018; 68: 394-424. https://doi.org/10.3322/caac.21492

[2] WOODARD GA, JONES KD, JABLONS DM. Lung Cancer Staging and Prognosis. Cancer Treat Res 2016; 170: 47-75. https://doi.org/10.1007/978-3-319-40389-2_3

[3] KISS N, ISENRING E, GOUGH K, KRISHNASAMY M. The prevalence of weight loss during (chemo)radiotherapy treatment for lung cancer and associated patient- and treatmentrelated factors. Clin Nutr 2014; 33: 1074-1080. https://doi. org/10.1016/j.clnu.2013.11.013

[4] BOVIO G, FONTE ML, BAIARDI P. Prevalence of upper gastrointestinal symptoms and their influence on nutritional state and performance status in patients with different primary tumors receiving palliative care. Am J Hosp Palliat Care 2014; 31: 20-26. https://doi.org/10.1177/1049909112474713

[5] SANCHEZ-LARA K, UGALDE-MORALES E, MOTOLA-KUBA D, GREEN D. Gastrointestinal symptoms and weight loss in cancer patients receiving chemotherapy. Br J Nutr 2013; 109: 894-897. https://doi.org/10.1017/ S0007114512002073

[6] SANCHEZ-LARA K, TURCOTT JG, JUAREZ E, GUEVARA P, NUNEZ-VALENCIA $C$ et al. Association of nutrition parameters including bioelectrical impedance and systemic inflammatory response with quality of life and prognosis in patients with advanced non-small-cell lung cancer: a prospective study. Nutr Cancer 2012; 64: 526-534. https://doi.org/10.1080/01635581.2012.668744 
[7] PACCAGNELLA A, MORELLO M, DA MOSTO MC, BARUFFI C, MARCON ML et al. Early nutritional intervention improves treatment tolerance and outcomes in head and neck cancer patients undergoing concurrent chemoradiotherapy. Support Care Cancer 2010; 18: 837-845. https:// doi.org/10.1007/s00520-009-0717-0

[8] HASENBERG T, ESSENBREIS M, HEROLD A, POST S, SHANG E. Early supplementation of parenteral nutrition is capable of improving quality of life, chemotherapy-related toxicity and body composition in patients with advanced colorectal carcinoma undergoing palliative treatment: results from a prospective, randomized clinical trial. Colorectal Dis 2010; 12: e190-199. https://doi.org/10.1111/j.14631318.2009.02111.x

[9] GAVAZZI C, COLATRUGLIO S, VALORIANI F, MAZZAFERRO V, SABBATINI A et al. Impact of home enteral nutrition in malnourished patients with upper gastrointestinal cancer: A multicentre randomised clinical trial. Eur J Cancer 2016; 64: 107-112. https://doi.org/10.1016/j.ejca.2016.05.032

[10] TRESTINI I, CARBOGNIN L, SPERDUTI I, BONAIUTO C, AURIEMMA A et al. Prognostic impact of early nutritional support in patients affected by locally advanced and metastatic pancreatic ductal adenocarcinoma undergoing chemotherapy. Eur J Clin Nutr 2018; 72: 772-779. https:// doi.org/10.1038/s41430-018-0155-5

[11] LAVIANO A, KOVERECH A, MARI A. Cachexia: clinical features when inflammation drives malnutrition. Proc Nutr Soc 2015; 74: 348-354. https://doi.org/10.1017/ S0029665115000117

[12] ONODERA T, GOSEKI N, KOSAKI G. [Prognostic nutritional index in gastrointestinal surgery of malnourished cancer patients]. Nihon Geka Gakkai Zasshi 1984; 85: 10011005.

[13] SAKURAI K, TAMURA T, TOYOKAWA T, AMANO R, KUBO $\mathrm{N}$ et al. Low Preoperative Prognostic Nutritional Index Predicts Poor Survival Post-gastrectomy in Elderly Patients with Gastric Cancer. Ann Surg Oncol 2016; 23: 3669 3676. https://doi.org/10.1245/s10434-016-5272-6

[14] HONG S, ZHOU T, FANG W, XUE C, HU Z et al. The prognostic nutritional index (PNI) predicts overall survival of small-cell lung cancer patients. Tumour Biol 2015; 36: 33893397. https://doi.org/10.1007/s13277-014-2973-y

[15] GENG Y, QI Q, SUN M, CHEN H, WANG P et al. Prognostic nutritional index predicts survival and correlates with systemic inflammatory response in advanced pancreatic cancer. Eur J Surg Oncol 2015; 41: 1508-1514. https://doi. org/10.1016/j.ejso.2015.07.022

[16] VAUGHAN VC, MARTIN P, LEWANDOWSKI PA. Cancer cachexia: impact, mechanisms and emerging treatments. J Cachexia Sarcopenia Muscle 2013; 4: 95-109. https://doi. org/10.1007/s13539-012-0087-1

[17] VAN DER MEIJ BS, SCHOONBEEK CP, SMIT EF, MUSCARITOLI M, VAN LEEUWEN PA et al. Pre-cachexia and cachexia at diagnosis of stage III non-small-cell lung carcinoma: an exploratory study comparing two consensus-based frameworks. Br J Nutr 2013; 109: 2231-2239. https://doi. org/10.1017/S0007114512004527
[18] KISS N. Nutrition support and dietary interventions for patients with lung cancer: current insights. Lung Cancer (Auckl) 2016; 7: 1-9. https://doi.org/10.2147/LCTT.S85347

[19] HEBUTERNE X, LEMARIE E, MICHALLET M, DE MONTREUIL CB, SCHNEIDER SM et al. Prevalence of malnutrition and current use of nutrition support in patients with cancer. JPEN J Parenter Enteral Nutr 2014; 38: 196-204. https://doi.org/10.1177/0148607113502674

[20] GUPTA D, LIS CG. Pretreatment serum albumin as a predictor of cancer survival: a systematic review of the epidemiological literature. Nutr J 2010; 9: 69. https://doi. org/10.1186/1475-2891-9-69

[21] CAMPBELL PT, NEWTON CC, DEHAL AN, JACOBS EJ, PATEL AV et al. Impact of body mass index on survival after colorectal cancer diagnosis: the Cancer Prevention Study-II Nutrition Cohort. J Clin Oncol 2012; 30: 42-52. https://doi. org/10.1200/JCO.2011.38.0287

[22] FURNESS K, SILVERS MA, SAVVA J, HUGGINS CE, TRU$\mathrm{BY} \mathrm{H}$ et al. Long-term follow-up of the potential benefits of early nutritional intervention in adults with upper gastrointestinal cancer: a pilot randomised trial. Support Care Cancer 2017; 25: 3587-3593. https://doi.org/10.1007/s00520017-3789-2

[23] SANTARPIA L, ALFONSI L, PASANISI F, DE CAPRIO C, SCALFI L et al. Predictive factors of survival in patients with peritoneal carcinomatosis on home parenteral nutrition. Nutrition 2006; 22: 355-360. https://doi.org/10.1016/j. nut.2005.06.011

[24] MAISEY NR, NORMAN A, WATSON M, ALLEN MJ, HILL ME et al. Baseline quality of life predicts survival in patients with advanced colorectal cancer. Eur J Cancer 2002; 38: 1351-1357. https://doi.org/10.1016/s09598049(02)00098-9

[25] PROCTOR MJ, MORRISON DS, TALWAR D, BALMER SM, FLETCHER CD et al. A comparison of inflammationbased prognostic scores in patients with cancer. A Glasgow Inflammation Outcome Study. Eur J Cancer 2011; 47: 2633 2641. https://doi.org/10.1016/j.ejca.2011.03.028

[26] HSIEH MC, WANG SH, CHUAH SK, LIN YH, LAN J et al. A Prognostic Model Using Inflammation- and Nutrition-Based Scores in Patients With Metastatic Gastric Adenocarcinoma Treated With Chemotherapy. Medicine (Baltimore) 2016; 95: e3504. https://doi.org/10.1097/MD.0000000000003504

[27] MIGITA K, TAKAYAMA T, SAEKI K, MATSUMOTO S, WAKATSUKI $\mathrm{K}$ et al. The prognostic nutritional index predicts long-term outcomes of gastric cancer patients independent of tumor stage. Ann Surg Oncol 2013; 20: 2647-2654. https://doi.org/10.1245/s10434-013-2926-5

[28] MOHRI Y, INOUE Y, TANAKA K, HIRO J, UCHIDA K et al. Prognostic nutritional index predicts postoperative outcome in colorectal cancer. World J Surg 2013; 37: 2688-2692. https://doi.org/10.1007/s00268-013-2156-9

[29] SUN K, CHEN S, XU J, LI G, HE Y. The prognostic significance of the prognostic nutritional index in cancer: a systematic review and meta-analysis. J Cancer Res Clin Oncol 2014; 140: 1537-1549. https://doi.org/10.1007/s00432-0141714-3 
[30] WANG Z, WANG Y, ZHANG X, ZHANG T. Pretreatment prognostic nutritional index as a prognostic factor in lung cancer: Review and meta-analysis. Clin Chim Acta 2018; 486: 303-310. https://doi.org/10.1016/j.cca.2018.08.030

[31] JIN S, CAO S, XU S, WANG C, MENG Q et al. Clinical impact of pretreatment prognostic nutritional index (PNI) in small cell lung cancer patients treated with platinum-based chemotherapy. Clin Respir J 2018; 12: 2433-2440. https:// doi.org/10.1111/crj.12925

[32] YE LL, OEI RW, KONG FF, DU CR, ZHAI RP et al. The prognostic value of preoperative prognostic nutritional index in patients with hypopharyngeal squamous cell carcinoma: a retrospective study. J Transl Med 2018; 16: 12. https://doi. org/10.1186/s12967-018-1391-0
[33] KWON WA, KIM S, KIM SH, JOUNG JY, SEO HK et al. Pretreatment Prognostic Nutritional Index Is an Independent Predictor of Survival in Patients With Metastatic Renal Cell Carcinoma Treated With Targeted Therapy. Clin Genitourin Cancer 2017; 15: 100-111. https://doi.org/10.1016/j. clgc.2016.07.025

[34] ARRIETA O, MICHEL ORTEGA RM, VILLANUEVA-RODRIGUEZ G, SERNA-THOME MG, FLORES-ESTRADA $\mathrm{D}$ et al. Association of nutritional status and serum albumin levels with development of toxicity in patients with advanced non-small cell lung cancer treated with paclitaxel-cisplatin chemotherapy: a prospective study. BMC Cancer 2010; 10: 50. https://doi.org/10.1186/1471-2407-10-50 